\title{
Neurological Complications of the COVID-19 Pandemic: what is Known, what has Ensued and what the Pandemic Portend?
}

\author{
Rebbeca Grysiewicz D0 ${ }^{1}$, Ulrike Klueh², Daniel L Menkes ${ }^{1}$ \\ ${ }^{1}$ Neurology Department, Oakland University William Beaumont School of Medicine, USA \\ ${ }^{2}$ Department of Biomedical Engineering, Wayne State University, USA
}

Submission: May 11, 2020; Published: June 03, 2020

*Corresponding author: Daniel L Menkes, Chair of Neurology, 3555 West 13 Mile Road, Suite N120, Royal Oak, MI 48073, USA

Abstract

The current COVID-19 pandemic is a rapidly evolving situation in which potential neurological complications are beginning to manifest although the full spectrum of the neurological complications of this infection have yet to be fully elucidated. Several potential mechanisms by which neurological diseases may arise as an epiphenomenon include hypercoagulability, molecular mimicry, and cytokine storm. This article reviews the available literature and postulates potential neurological complications of COVID-19 infections based on these pathophysiologies. Although no specific treatment has been proven to be effective to date, preventive measures and management of COVID-19 associated complications is currently recommended.

\section{Introduction}

An important medical axiom is that the host's immune response to the pathogen often determines the clinical outcome more than the pathogen itself-especially for viral illnesses. The immune system is tasked with distinguishing self from foreign antigens then mounting a proportionate response to would-be invaders such as bacteria and viruses. A novel virus officially known as severe acute respiratory syndrome coronavirus 2 (SARS-CoV-2) has resulted in a worldwide pandemic of a disease designated as coronavirus disease or COVID-19; the term that will be used in this manuscript [1]. Coronaviruses are enveloped RNA viruses found in mammals and birds [2]. One source opined that they originated from a common ancestor that affected bats [3]. A more recent publication bolstered this hypothesis in that a phylogenetic analysis indicated that SARS-CoV-2 is similar to the coronavirus circulating in Rhinolophus (horseshoe bats) [4] Given the findings of these genomic investigations and the presence of some bats and live animals in the seafood market in Wuhan, China, it has been hypothesized that COVID-19 may have originated from bats or their guano associated with contaminated materials in a wet market or its environs $[5,6]$. This current global pandemic has resulted in nearly 1,092,815 infections and over 64,283 deaths in the United States including the 50 states, District of Columbia, Guam, the Northern Mariana Islands, Puerto Rico, and the U.S Virgin Islands as of May 3, 2020; numbers that are likely to increase [7]. Globally, as of that date, 3.6 million confirmed cases were reported with over 247,705 deaths representing a mortality rate of approximately $7 \%$ [8]. However, worldwide mortality rates have a wide range from $0.2 \%$ reported in Bahrain to $21.4 \%$ in Nicaragua [9]. While usually presenting as a respiratory infection, COVID-19 can lead to a variety of complications including acute respiratory failure, pneumonia, Acute Respiratory Distress Syndrome (ARDS), acute organ damage (liver, kidney and cardiac), septic shock, Disseminated Intravascular Coagulation (DIC), thrombosis and rhabdomyolysis[10]. Presenting neurological symptoms, comprising $23 \%$ of patients in one report, were nonspecific myalgias and headaches [11]. In a retrospective review of 214 patients diagnosed with COVID-19, Mao et al reported anosmia in 11 people (5.1\%) patients and ageusia in 12 (5.6\%) [12]. Other neurological manifestations, which tend to be significantly more prevalent with severe disease, include acute cerebrovascular disease $0.8 \%$ in non-severe infections, $5.7 \%$ in severe), impaired consciousness (2.4\% in non-severe and $14 . \%$ in severe), and skeletal muscle injury ( $4.8 \%$ in non-severe infections, $19.3 \%$ in severe)[13]. Another publication summarized the neurological complications of COVID-19 to include headache, dizziness, myalgia and anosmia, as well as cases of encephalopathy, 
encephalitis, necrotizing hemorrhagic encephalopathy, stroke, epileptic seizures, rhabdomyolysis and Guillain-Barré syndrome [14]. Thus, it is likely that other neurological complications may arise through the pathophysiology of one or more of the following; molecular mimicry, hypercoagulability, and cytokine storm. This review article will summarize the currently known neurological complications and speculate on additional potential complications of this evolving pandemic.

\section{Methods}

The keywords neurological complications, hypercoagulability, molecular mimicry, COVID-19, coronavirus, cytokine storm, stroke and Guillain-Barré were used for a database review. The databases queried included Medline, PubMed, Ovid, MedlinePlus, and Google Scholar. These resources were utilized to assesses major complications of COVID-19 to include hypercoagulability, molecular mimicry, and cytokine storm.

\section{Hypercoagulability}

Viral infections are associated with all aspects of coagulation disorders including primary hemostasis, coagulation and fibrinolysis leading to complications including thrombosis, disseminated intravascular coagulation and hemorrhage singularly or in combination [15]. A small case series of COVID-19 associated hypercoagulability resulting in widespread thrombosis including limb ischemia and multiple territory cerebral infarction was reported [16]. A subsequent publication reported that a seven-fold increase in acute, large vessel strokes were observed in young adults affected with COVID-19 [17, 18]. Coagulopathy and vascular endothelial dysfunction have been hypothesized to be the responsible mechanisms [19]. Given the association of increased arterial and venous hypercoagulability with COVID-19, a consensus statement was published that provided guidelines for the treatment of these disorders but did not make evidencebased recommendations specific to COVID-19 [20]. In the absence of prospective trials to guide therapy, the authors recommend using current standards of care with a lower threshold for antithrombotic and anticoagulant therapies.

\section{Molecular Mimicry}

Molecular mimicry occurs when peptides from pathogens share a sequence or structural similarities with self-antigens [21]. Several autoimmune diseases have been postulated to occur from molecular mimicry including the Guillain-Barré syndrome, chronic inflammatory demyelinating polyradiculoneuropathy [CIDP] neuromyelitis optica spectrum disorder and multiple sclerosis [22-25]. Perez noted that coronaviruses, including COVID-19, have neuroinvasive potential such that encephalitis as well as postinfectious, immune-mediated complications in the convalescent period might ensue [26]. Other authors prognosticated that COVID-19 induced multiorgan dysfunction with encephalopathy, with or without encephalitis, might engender diverse types of neuropsychiatric symptoms, such as encephalopathy, mood changes, psychosis, neuromuscular dysfunction, or demyelinating processes [27]. However, a recent review did not find evidence to support an increased incidence of COVID-19 associated autoimmune disorders [28]. Nonetheless, sporadic associations have been reported including one case of a COVID-19 associated acute motor axonal neuropathy presentation of the Guillain-Barré syndrome [29]. A subsequent publication reported two GuillainBarré variants associated with COVID-19 including Miller Fisher syndrome and polyneuritis cranialis [30]. Other neuromuscular disorders associated with COVID-19 were summarized in a recent review, which also made treatment recommendations based upon available literature [31]. A similar publication regarding the treatment of multiple sclerosis during the COVID-19 epidemic suggested that it was safe to initiate treatment with interferon beta and glatiramer acetate, and that is was "perhaps safe to start teriflunomide and dimethyl fumarate in children and young adults who are otherwise healthy"[32]. These authors further recommend starting or switching to natalizumab in patients with more severe disease rather than using alemtuzumab, cladribine or ocrelizumab, “... because the risk of systemic immunosuppression is lower and prolonged lymphocyte depletion does not occur" and concluded with a statement that a risk to benefit assessment should be conducted for other agents [33]. Moreover, these authors further stated that disease modifying therapy could generally be continued but that corticosteroids for acute exacerbations be used more judiciously. Notwithstanding these observations and recommendations, the COVID-19 pandemic has not resulted in a statistically significant increase in either peripheral or central nervous system demyelinating diseases.

\section{Cytokine Storm}

Cytokine storm is the deadly uncontrolled systemic inflammatory response resulting from the release of large amounts of pro-inflammatory cytokines (IFN- $\alpha$, IFN- $\gamma$, IL-1 $\beta$, IL6, IL-12, IL-18, IL-33, TNF- $\alpha$, TGF $\beta$, etc.) and chemokines (CCL2, CCL3, CCL5, CXCL8, CXCL9, CXCL10, etc.) by immune effector cells in SARS-CoV infection [34]. Primary infection is first countered by the innate immune system that has no immunological memory followed by recruitment of the adaptive immune system capable of distinguishing foreign from autoantigens [35]. With any viral infection, including COVID-19, excessive viral replication leads to cell death enabling the release of viral particles, which may incite an immune response. Infection of monocytes/macrophages and/ or recruitment of uninfected immune cells can result in massive inflammatory responses later in the disease characterized by uncontrolled production of pro-inflammatory mediators which may induce a cytokine storm and its complications including ARDS [36]. This is a complex process in which there is an excessive immune response to external stimuli and has been linked to rapid clinical deterioration in patients infected with COVID-19 resulting in acute respiratory distress syndrome [ARDS] and multiorgan 
failure [37]. These authors noted that most of the affected patients had mild symptoms on presentation but would have an abrupt deterioration including during the recovery phase of the illness. Optimal treatment of cytokine storm has yet to be determined although one publication recommended consideration of the following: steroids, intravenous immunoglobulin, selective cytokine blockade (e.g. anakinra or tocilizumab) [38]. These authors recommended assessing for a subgroup of COVID-19 infected patients with hyperinflammation using laboratory trends (e.g. increasing ferritin, decreasing platelet counts, or erythrocyte sedimentation rate) and a scoring system originally designed to detect Secondary Hemophagocytic Lymphohistiocytosis (sHLH); a hyperinflammatory syndrome characterized by a fulminant and fatal hypercytokinemia with multiorgan failure [39]. Those COVID-19 affected patients with evidence of an incipient cytokine storm should be considered for treatment with immunomodulatory agents.

\section{Reducing the Probability of Neurological Complica- tions}

The probability of encountering neurological complications is predicated upon reducing the probability of initial COVID-19 infection, methods designed to attenuate viral replication, and immunomodulatory treatments. Given the paucity of prospective randomized trials, expert opinion based on past experiences currently guides treatment recommendations. Reducing personto-person transmission by social distancing, proper hygiene and the use of facemasks has been advocated [40]. Numerous treatments for those infected with COVID-19 have been proposed such that the National Institute of Health [NIH] recently published treatment guidelines for COVID-19 infection [41]. NIH stated that no medication has been proven safe and effective for the treatment of COVID-19 and that testing within the context of a clinical trial is recommended. NIH further recommended that patients who were previously prescribed antihypertensive agents, statins and corticosteroids should continue these medications but they should not be given de novo save for the possible role of low dose corticosteroids in "refractory shock" and in specific cases of preterm birth. Subsequent to this, preliminary results from a trial sponsored by the National Institute for Allergy and Infectious Diseases (NIAID), hospitalized patients with advanced COVID-19 treated with remdesivir had a $31 \%$ faster time to recovery than those who received placebo $(\mathrm{p}<0.001)$. Specifically, the median time to recovery was 11 days for patients treated with remdesivir compared with 15 days for those who received placebo. Results also suggested a survival benefit, with a mortality rate of $8.0 \%$ for the group receiving remdesivir versus $11.6 \%$ for the placebo group $(p=0.059)$ although the latter did not achieve statistical significance [42]. The results of this study prompted the Food and Drug administration to authorize remdesivir for emergency use in patients with suspected or laboratory confirmed COVID-19 and severe disease defined as $\mathrm{SpO}_{2} \leq 94 \%$ on room air, requiring supplemental oxygen, mechanical ventilation, or extracorporeal membrane oxygenation (ECMO) [43]. However, a contemporary study published in the Lancet found no statistically significant benefit from remdesivir [44]. In the absence of specific evidence based recommendations, clinicians are advised to address individual patients based on currently available treatment guidelines for patient's diseases that exist concurrently with a supervening COVID-19 infection.

\section{Conclusion}

COVID-19 is a novel disease that results from an infection with a coronavirus, an enveloped RNA virus that likely originated in bats. The primary infection is transmitted from person to person as an upper respiratory infection resulting in a continuum of clinical illness ranging from an asymptomatic carrier state to a hyperinflammatory immune dysregulatory state resulting in a cytokine storm leading to complications including ARDS to multiorgan failure. Notwithstanding, the evolving medical literature has not seen a significant increase in neurological complications aside from reports of an increased risk of stroke and the encephalopathy that often accompanies multiorgan dysfunction and systemic inflammation. Although no specific treatment has been found to be effective for COVID-19, the FDA has approved the use of remdesivir in critically ill patients. Providers who encounter neurological comorbidities in COVID-19 infected patients should treat these illnesses in accordance with current evidence-based medicine guidelines.

\section{References}

1. Naming the coronavirus disease (COVID-19) and the virus that causes it. Retrieved from https://www.who.int/emergencies/diseases/novelcoronavirus-2019/technical-guidance/naming-the-coronavirusdisease-(covid-2019)-and-the-virus-that-causes-it.

2. Su S, Wong G, Shi W, (2016) Epidemiology, Genetic Recombination and Pathogenesis of Coronaviruses. Trends in Microbiology 24: 490-502.

3. Woo PCY, Lau SKP, Lam CSF, Lau CCY, Tsang AKL, et al. (2012) Discovery of seven novel mammalian and avian coronaviruses in Delta coronavirus supports bat coronaviruses as the gene source of Alpha coronavirus and Beta coronavirus and avian coronaviruses as the gene source of Gamma coronavirus and Delta coronavirus. Journal of Virology 86(7): 3995-4008.

4. Lai CC, Shih TP, Ko WC, Tan HJ, Hsueh PR. Severe acute respiratory syndrome coronavirus 2 (SARS-CoV-2) and coronavirus disease-2019 (COVID-19): The epidemic and the challenges. HYPERLINK "https:// www.ncbi.nlm.nih.gov/pmc/articles/PMC7127800/" Int J Antimicrob Agents. 2020 Feb 17.

5. Jiang S, Du L, Shi Z (2020) An emerging coronavirus causing pneumonia outbreak in Wuhan, China: calling for developing therapeutic and prophylactic strategies. Emerg Microbes Infect 9(1): 275-277.

6. Zhou P, Yang XL, Wang XG, Hu B, Zhang L, et al. (2020) A pneumonia outbreak associated with a new coronavirus of probable bat origin. Nature 579: 270-273.

7. Cases of Coronavirus Disease (COVID-19) in the US. Centers for Disease Control and Prevention. Retrieved from https://www.cdc.gov/ coronavirus/2019-ncov/cases-updates/cases-in-us.html 


\section{Open Access Journal of Neurology \& Neurosurgery}

8. Coronavirus live stats. Retrieved from https://coronavirus-stats.live/

9. Maps and Trends. Mortality Analysis. Johns Hopkins University Coronavirus Resource Center. Retrieved from https://coronavirus.jhu. edu/data/mortality

10. Complications Coronavirus can Cause. Retrieved from https://www. webmd.com/lung/coronavirus-complications\#1

11. Chang D, Lin M, Wei L, Xie L, Zhu G, et al. (2020) Epidemiologic and clinical characteristics of novel coronavirus infections involving 13 patients outside Wuhan, China. JAMA 23(11):1092-1093.

12. Mao L, Wang M, Chen S, Quanwei He, Jiang Chang, et al. (2020) Neurological manifestations of hospitalized patients with COVID-19 in Wuhan, China: a retrospective case series study. MedR.

13. Yasgur BS Covid-19: First Data Confirm Neurologic Symptoms Common. Retrieved from https://www.medscape.com/ viewarticle/928848\#vp_2

14. Carod-Artal FJ (2020) Neurological complications of coronavirus and COVID-19. Re Neurol 70(9): 311-322.

15. Goeijenbier M, van Wissen M, van de Weg C et al. (2012) Review: Viral Infections and Mechanisms of Thrombosis and Bleeding. Journal of Medical Virology 84: 1680-1696.

16. Zhang Y, Xiao M, Zhang S Coagulopathy and Antiphospholipid Antibodies in Patients with Covid-19. Retrieved from https://www. nejm.org/doi/full/10.1056/NEJMc2007575

17. Mc Namara D (2020) COVID-19 Linked to Large Vessel Stroke in Young Adults. Retrieved from https://www.medscape.com/ viewarticle /929345? nlid=135229_5653\&src=wnl_newsalrt daily_200425_MSCPEDIT\&uac=346751FN\&impID=2359817\&faf=1

18. Oxley TJ, Mocco J, Majidi S Large-Vessel Stroke as a Presenting Feature of Covid-19 in the Young. Retrieved from https://www.nejm.org/doi/ full/10.1056/NEJMc2009787.

19. Zhou F, Yu T, Du R, Guohui Fan, Ying Liu, et al. (2020) Clinical course and risk factors for mortality of adult inpatients with COVID-19 in Wuhan, China: a retrospective cohort study. Lancet 395(10229): 1054-1062.

20. Bikdeli B, Madhavan MV, Jimenez D, Chuich T, Dreyfus I, et al. (2020) COVID-19 and Thrombotic or Thromboembolic Disease: Implications for Prevention, Antithrombotic Therapy, and Follow-up: JACC State-ofthe-Art Review J Am Coll Cardiol 75(23): 2950-2973.

21. Libbey JE, McCoy LL, Fujinami RS (2007) Molecular Mimicry in Multiple Sclerosis. International Review of Neurobiology. 79: 127-147.

22. Ang CM, Jacobs BC, Laman JD (2004) The Guillain-Barré syndrome: a true case of molecular mimicry. Trends Immunol 25: 61-66.

23. Marinos C Dalakas, Medscape (2011) Advances in the diagnosis, pathogenesis and treatment of CIDP. Nat Rev Neurol 7(9): 507-517.

24. Zhong X, Zhou Y, Lu T, Zhanhang Wang, Ling Fang, et al. (2018) Infections in neuromyelitis optica spectrum disorder. Journal of Clinical Neuroscience 47: 14-19.

25. McCoy L, Tsunoda I, Fujinami RS (2006) Multiple sclerosis and virus induced immune responses: Autoimmunity can be primed by molecular mimicry and augmented by bystander activation. Journal Autoimmunity 39(1): 9-19.

26. Perez CA Looking ahead: The risk of neurologic complications due to COVID-19. Retrieved from https://cp.neurology.org/content/ early/2020/04/08/CPJ.0000000000000836.abstract.

27. Troyer EA, Kohn JN, Hong S (2020) Are we facing a crashing wave of neuropsychiatric sequelae of COVID-19? Neuropsychiatric symptoms and potential immunologic mechanisms. Brain, Behavior, and Immunity 87: 34-39.
28. Cappello F (2020) Is COVID-19 a proteiform disease inducing also molecular mimicry phenomena? Cell Stress and Chaperones 25(3): 381-382.

29. Sedaghat Z, Karimi N Guillain-Barré (2020) syndrome associated with COVID-19 infection: A case report. Retrieved from https://www. sciencedirect.com/science/article/pii/S0967586820308821.

30. Gutiérrez-Ortiz G, Méndez A, Rodrigo-Rey S Miller Fisher Syndrome and polyneuritis cranialis in COVID-19. Retrieved from https://n.neurology. org/content/early/2020/04/17/WNL.0000000000009619.

31. Guidon AC, Amato AA COVID-19 and Neuromuscular Disorders. Retrieved from https://n.neurology.org/content/neurology/ early/2020/04/13/WNL.0000000000009566.full.pdf.

32. Brownlee W, Bourdette D, Broadley S, Killestein J, Ciccarelli O Treating multiple sclerosis and neuromyelitis optica spectrum disorder during the COVID-19 pandemic. Retrieved from https://n.neurology.org/ content/neurology/early/2020/04/01/WNL.0000000000009507. full.pdf.

33. Ibid.

34. Li X, Geng M, Peng Y, Meng L, Lu S (2020) Molecular immune pathogenesis and diagnosis of COVID-19. Journal of Pharmaceutical Analysis 10(2): 102-108.

35. Warrington R, Watson W, Kim HL (2011) An introduction to immunology and immunopathology. All Asth Clin Immun 7: S1. https://doi.org/10.1186/1710-1492-7-S1-S1.

36. Felsenstein S, Herbert JA, McNamara PS, Hedrich CM. COVID-19: Immunology and treatment options. Clin Immunol 2020 Apr 27: 108448. doi: 10.1016/j.clim.2020.108448.

37. Ye Q Wang B, Mao J The pathogenesis and treatment of the 'Cytokine Storm' in COVID-19. J Infect 2020 Apr 10. pii: S0163-4453(20)301651. doi: 10.1016/j.jinf.2020.03.037.

38. Mehta P, McAuley DF, Brown M, Sanchez E, Tattersall RS, et al. (2020) COVID-19: consider cytokine storm syndromes and immunosuppression. Lancet 395(10229): 1033-1034.

39. Fardet L, Galicier L, Lambotte O, Christophe Marzac, Cedric Aumont, et al. (2014) Development and validation of the HScore, a score for the diagnosis of reactive hemophagocytic syndrome. Arthritis Rheumatol 66(9): 2613-2620.

40. Eikenberry SE, Mancuso M, Iboi $\mathrm{E}$ et al. To mask or not to mask: Modeling the potential for face mask use by the general public to curtail the COVID-19 pandemic. Infect Dis Model. 2020 Apr 21; 5: 293308. doi: 10.1016/j.idm.2020.04.001. e Collection 2020.

41. National Institute of Health. COVID-19 treatment guidelines. Retrieved from https://covid19treatmentguidelines.nih.gov/overview/

42. National Institute of Allergy and Infectious Diseases. NIH Clinical Trial Shows Remdesivir Accelerates Recovery from Advanced COVID-19. Retrieved from https://www.niaid.nih.gov/news-events/nih-clinicaltrial-shows-remdesivir-accelerates-recovery-advanced-covid-19

43. US Food and Drug Administration. Retrieved from https://www.fda. gov/media/137564/download.

44. Wang Y, Zhang D, Du G et al. Remdesivir in adults with severe COVID-19. a randomised, double blind, placebo-controlled multicentre trial. Retrieved from https://www.thelancet.com/journals/lancet/article/ PIIS0140-6736(20)31022-9/fulltext. 
(C) (i) This work is licensed under Creative BY DOI: 10.19080/OAJNN.2020.13.555867

\section{Your next submission with Juniper Publishers will reach you the below assets}

- Quality Editorial service

- Swift Peer Review

- Reprints availability

- E-prints Service

- Manuscript Podcast for convenient understanding

- Global attainment for your research

- Manuscript accessibility in different formats

( Pdf, E-pub, Full Text, Audio)

- Unceasing customer service

Track the below URL for one-step submission

https://juniperpublishers.com/online-submission.php 